\title{
The Effect of Carbon Source, Temperature and Aeration on the Production of Ascosteroside, a Novel Antifungal Agent, by Ascotricha amphitricha
}

\author{
Susan E. Lowe*, Donald R. Gustavson, David S. Meyers", Judith A. Veitch, \\ SALVATORE Forenza and Kin Sing Lam
}

Bristol-Myers Squibb Pharmaceutical Research Institute, 5 Research Parkway, Wallingford, CT 06492-7660, U.S.A.

(Received for publication October 14, 1996)

\begin{abstract}
This paper describes the optimization of production of ascosteroside, a novel antifungal agent with an $\alpha$-linked glycoside of a lanosterone-type triterpenoid structure. Glucose, sorbose and inositol were determined to be the best carbon sources for the production of ascosteroside. Temperature affected levels of ascosteroside, with production being highest at $16^{\circ} \mathrm{C}$ with $1 \%$ glucose, and lowest at $32^{\circ} \mathrm{C}$. Dissolved oxygen levels were found to be critical in the production of ascosteroside in fermenter cultures. In order for production of ascosteroside to occur in fermenter cultures, the threshold level of dissolved oxygen was found to be above $26 \%$.
\end{abstract}

In our continuing search for novel antifungal agents produced by microorganisms, a novel antifungal agent ascosteroside with a glycosylated lanostane type triterpenoid structure, was isolated from the fermentation of Ascotricha amphitricha ${ }^{1,2)}$. Ascosteroside is active against several Candida species, Saccharomyces cerevisiae and filamentous fungi, and has little or no activity against bacteria ${ }^{1)}$. The mode of action of ascosteroside is not known, however, it has been determined that it does not inhibit the biosynthesis of sterol, protein and nucleic acid, and has no effect on membrane integrity in Candida albicans ${ }^{11}$.

In order to obtain sufficient ascosteroside for expanded biological activity testing and clinical evaluation, large scale fermentation was necessary. This paper describes the studies of the effect of carbon source, temperature and oxygen on the production of ascosteroside and successful scale-up production of this compound in laboratory fermenter.

\section{Materials and Methods}

\section{Microorganism and Culture Conditions}

Ascotricha amphitricha was isolated from a soil sample collected from Kenya ${ }^{1}$, and has been deposited with the American Type Culture Collection as ATCC 74237. The culture was grown on a potato-dextrose agar slant for 7 days, and the surface growth of the slant was swabbed into $100 \mathrm{ml}$ of medium F4 in a 500-ml flask. Medium F4 contained the following per litre of distilled water: tryptone $5 \mathrm{~g}$, malt extract $3 \mathrm{~g}$, glucose $10 \mathrm{~g}$, and yeast extract $3 \mathrm{~g}$. The $\mathrm{pH}$ of the medium was 6.5 and was not adjusted prior to sterilization. The medium was sterilized for 30 minutes. All shake flask studies were carried out using narrow mouth flasks. Frozen vegetative preparations were prepared by mixing a culture grown for 3 days in medium $\mathrm{F} 4$ with an equal volume of $20 \%(\mathrm{w} / \mathrm{v})$ glycerol $/ 10 \%(\mathrm{w} / \mathrm{v})$ sucrose, and aliquots frozen in a dry ice-acetone bath, and stored at $-80^{\circ} \mathrm{C}$. From the frozen stock, $4 \mathrm{ml}$ was used as an inoculum into $100 \mathrm{ml}$ of medium F4. The culture was grown for 3 days and then $4 \%(\mathrm{v} / \mathrm{v})$ of the culture was used to inoculate medium $\mathrm{F} 4$, which was also used as the production medium. All cultures were grown in liquid media at $28^{\circ} \mathrm{C}$ by shaking at $250 \mathrm{rpm}$ unless stated otherwise.

\section{Fermenter Conditions}

Cultures were grown in a 15 litre Braun Biostat ED fermenter (B. Braun, Allentown, PA) containing 10 litre of medium $\mathrm{F} 4$. The $\mathrm{pH}$ of the medium was not adjusted prior to sterilization, and the medium was sterilized for 45 minutes. The fermenter cultures were grown at $28^{\circ} \mathrm{C}$, with an agitation rate of $500 \mathrm{rpm}$, airflow of IVVM and back pressure of 0.3 bar unless stated otherwise. The antifoam agent polypropylene glycol P-2000 was added to a final concentration of $0.01 \%(\mathrm{v} / \mathrm{v})$ prior to sterilization. Each fermenter was equipped with an oxygen probe, and measurements of dissolved oxygen were taken throughout the fermentation. The fermenters were inoculated with $400 \mathrm{ml}$ of a culture which had been

$\dagger$ Present address: Antitumor Fermentation Development, Bristol-Myers Squibb, Syracuse, New York, U.S.A. 
grown in flasks by shaking for 3 days as described above.

\section{Extraction}

Samples from the fermentation were mixed with an equal volume of ethyl acetate for 1 hour. After centrifugation, $1 \mathrm{ml}$ of the ethyl acetate layer was removed and dried under nitrogen, and stored at $-20^{\circ} \mathrm{C}$ until use.

\section{Analytical Methods}

Growth of the organism was determined by the \% sediment measured after centrifugation of $10 \mathrm{ml}$ of culture broth at $3000 \times g$ for 10 minutes. A correlation was established between \% sediment and dry weight and this was used to calculate the fungal dry weight of each fermentation. Samples were taken from the supernatant for determination of glucose and ammonia. Glucose was measured as a reducing sugar with dinitrosalicylic acid reagent ${ }^{3)}$. Ammonia was determined using the method of WeATHERBURN ${ }^{4)}$. Crude extracts were examined by HPLC using a Rainin "Short-One" C18 $(3 \mu) 10 \mathrm{~cm} \mathrm{~L}$ column with a solvent system of acetonitrile- $0.01 \mathrm{M}$ potassium phosphate (monobasic) buffer $\mathrm{pH} 3.5$ gradient with a flow rate of $1.2 \mathrm{ml} / \mathrm{minute}$ with UV detection at $230 \mathrm{~nm}^{2)}$.

\section{Biological Activity}

For antifungal activity, $S$. cerevisiae strain SC109 (Sc7) was used as the tester organism as described elsewhere ${ }^{1)}$.

\section{Results}

Effect of Carbon Source on

Ascosteroside Production

By using flask cultures with various carbon sources the amount of ascosteroside produced was determined using a biological assay of antifungal activity against

Fig. 1. Bioactivity of HPLC fractions of crude extract of A. amphitricha against $S$. cerevisiae (Sc7).

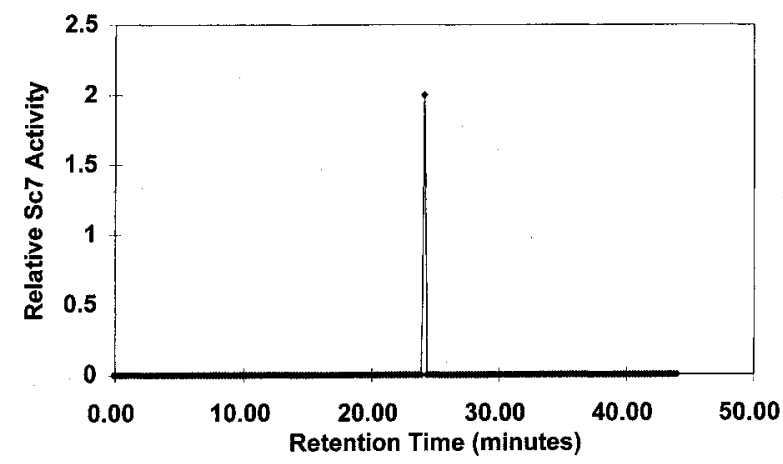

S. cerevisiae strain SC109 (Sc7). HPLC could not be used to accurately establish titers of ascosteroside in the crude extract due to the poor resolution of this compound. Ascosteroside was determined to be the only antifungal agent present in the crude extract as evidenced by microbiological assay of HPLC fractions (Fig. 1), and the retention time corresponded to the retention time of the pure compound ${ }^{2)}$. As a good correlation existed between Sc7 activity and pure ascosteroside, biological activity was used to determine ascosteroside production. The $\mathrm{pH}$ during growth with the different carbon sources increased throughout the fermentation, ending between 7.8 and 8.8 (Table 1). The amount of biomass formed varied, depending on the carbon source. Highest levels of ascosteroside were found when $A$. amphitricha was grown on glucose, sorbose, glucosamine and inositol. Due to the cost of sorbose, glucosamine and inositol, further studies were carried out with glucose.

\section{Effect of Glucose on Ascosteroside Production}

The effect of $1 \%, 3 \%$ and $5 \%$ glucose on production of ascosteroside was studied (Fig. 2). The rate of glucose consumption was similar with all three concentrations of glucose, and the $\mathrm{pH}$ of the fermentation increased above 7.0 once the glucose had been consumed, with the exception of $5 \%$ glucose where the $\mathrm{pH}$ remained around 5.0. Highest levels of ascosteroside were found with $3 \%$ glucose, and with 3 and $5 \%$ glucose production occurred prior to exhaustion of the substrate.

Table 1. The effect of carbon source on production of ascosteroside by $A$. amphitrich $a^{a}$.

\begin{tabular}{|c|c|c|c|}
\hline Carbon source $^{\mathbf{b}}$ & Final $\mathrm{pH}$ & $\begin{array}{c}\text { Dry weight } \\
(\mathrm{mg} / \mathrm{ml})\end{array}$ & $\begin{array}{c}\mathrm{Sc7} \\
(\mathrm{mm})\end{array}$ \\
\hline Glucose (control) & 8.7 & 5.8 & 9.0 \\
\hline Mannose & 8.5 & 6.1 & 6.5 \\
\hline Sorbose & 8.4 & 3.2 & 10.0 \\
\hline Galactose & 8.5 & 6.7 & 5.5 \\
\hline Glucosamine & 8.2 & 3.2 & 9.0 \\
\hline Lactose & 8.7 & 5.5 & 8.5 \\
\hline Inositol & 8.6 & 4.1 & 10.5 \\
\hline Dulcitol & 8.5 & 6.1 & 3.0 \\
\hline Mannitol & 8.0 & 6.1 & 6.0 \\
\hline Sorbitol & 8.2 & 6.1 & 8.5 \\
\hline Glycerol $(0.5 \%)$ & 8.5 & 7.9 & 4.0 \\
\hline Whey & 8.8 & 4.1 & 8.0 \\
\hline Choline & 8.6 & 2.0 & 0 \\
\hline Ethanolamine & 7.8 & 2.0 & 0 \\
\hline Base medium ${ }^{c}$ & 8.2 & 2.0 & 0 \\
\hline
\end{tabular}

a The culture was grown in flasks by shaking at $28^{\circ} \mathrm{C}$ and samples taken after 5,6 and 7 days of incubation.

b All carbon sources were present at $1 \%(\mathrm{w} / \mathrm{v})$ unless stated otherwise.

c The base medium contained tryptone, $5 \mathrm{~g}$; malt extract, $3 \mathrm{~g}$; yeast extract, $3 \mathrm{~g}$. 
Fig. 2. The effect of glucose concentration on ascosteroside production in shake flasks at $28^{\circ} \mathrm{C}$.

Glucose concentration (open symbols) and Sc7 activity (closed symbols) at $1 \%(\mathrm{O}, \mathbf{O}), 3 \%(\triangle, \boldsymbol{\Delta})$ and $5 \%$ glucose $(\square, \boldsymbol{\square})$.

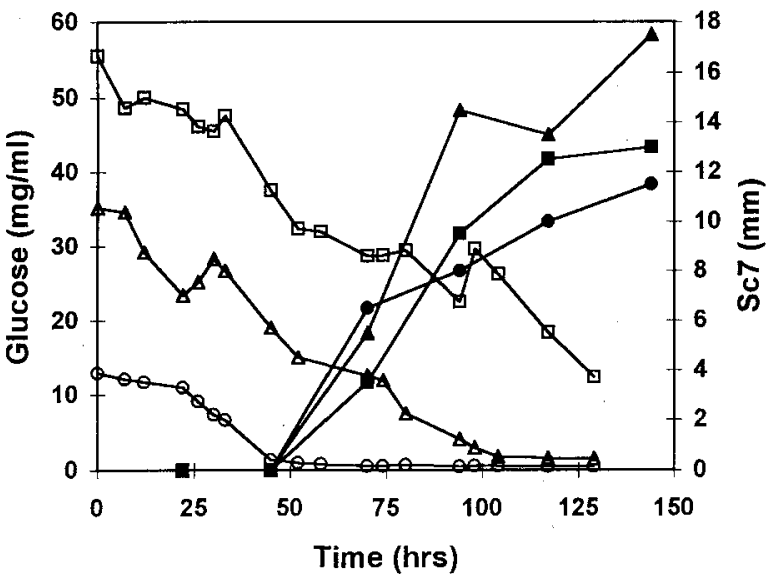

Production of Ascosteroside in a Fermenter

Using medium with $1 \%$ glucose and either 200 or $350 \mathrm{rpm}$ with $1 \mathrm{VVM}$ of aeration in the fermenters, the production of ascosteroside was not detected (Fig. 3). Increasing the agitation rate to $500 \mathrm{rpm}$ resulted in similar levels of antifungal activity being detected, compared with the shake flasks. Growth of A. amphitricha under the different conditions did not show any significant differences with respect to glucose consumption and biomass formation, with the active phase of growth occurring between $20 \sim 40$ hours. However, with the lowest agitation rate, ammonia production and consequently an increase in $\mathrm{pH}$, was significantly slower compared to growth at higher agitation speeds. The most significant difference between the fermentations was the amount of dissolved oxygen present during growth. During the early part of the fermentation oxygen consumption was high resulting in significant depletion to around $1 \%$ with stirring speeds of 200 and $350 \mathrm{rpm}$, and no antifungal activity was detected. At $500 \mathrm{rpm}$ the dissolved oxygen dropped to around $40 \%$ by 35 hours, before increasing back to $100 \%$, indicating that cellular growth had ceased at 35 hours and ascosteroside production coincided with the increase in dissolved oxygen levels. In other experiments, if dissolved oxygen levels dropped below $26 \%$, production of ascosteroside was not detected (Table 2). Ensuring that the minimum level of dissolved oxygen was above $40 \%$, using increased agitation or increased back pressure did not result in improved production of ascosteroside, and higher levels
Fig. 3. The effect of stirring speed on ascosteroside production by $A$. amphitricha in the fermenter.

(A) Glucose concentration (open symbols) and biomass levels (closed symbols) at $200 \mathrm{rpm}(O, \bullet), 350 \mathrm{rpm}(\triangle, \boldsymbol{\Delta})$ and $500 \mathrm{rpm}(\square, \square)$. (B) Dissolved oxygen levels (open symbols) and Sc7 activity (closed symbols) at $200 \mathrm{rpm}(O$, -), $350 \mathrm{rpm}(\triangle, \boldsymbol{\Delta})$ and $500 \mathrm{rpm}(\square, \boldsymbol{\square})$. (C) Ammonia levels (open symbols) and $\mathrm{pH}$ (closed symbols) at $200 \mathrm{rpm}$ $(\bigcirc, \bullet), 350 \mathrm{rpm}(\triangle, \boldsymbol{\Lambda})$ and $500 \mathrm{rpm}(\square, \boldsymbol{\square})$.

(A)

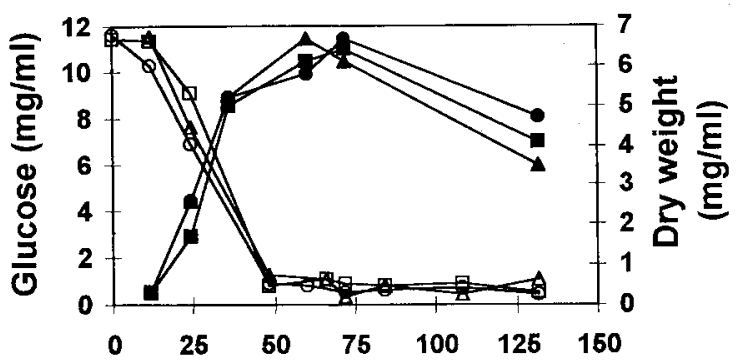

(B)

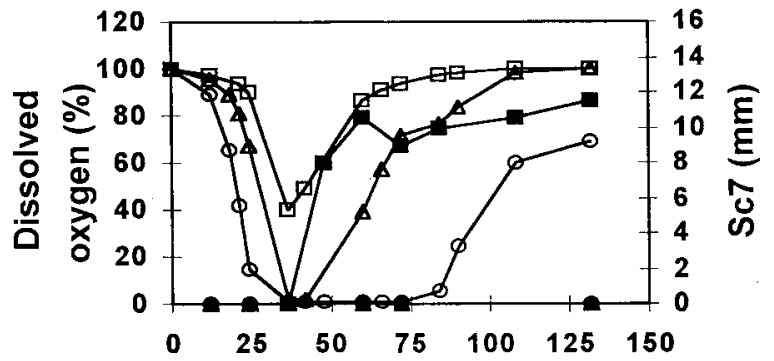

(C)

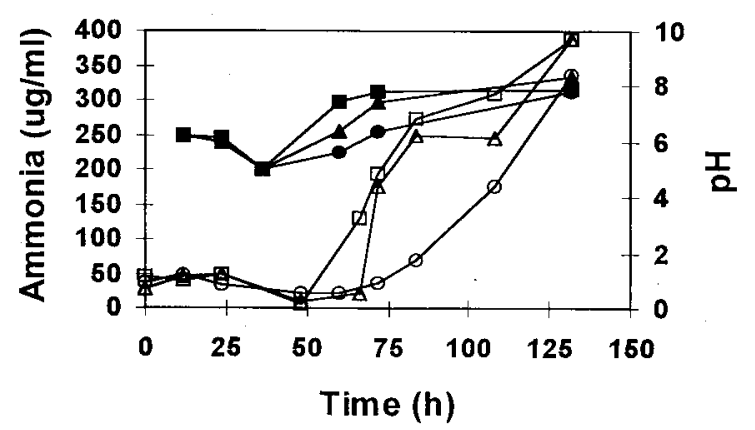

of oxygen actually inhibited production.

Effect of Glucose on Ascosteroside

Production in a Fermenter

With the fermenter being stirred at $500 \mathrm{rpm}$ and an aeration rate of $1 \mathrm{VVM}$, the production of ascosteroside in media containing $1 \%$ glucose and $3 \%$ glucose was examined (Fig. 4). Similar levels of biomass were formed under these conditions. The $\mathrm{pH}$ of the fermenter with $1 \%$ glucose increased during stationary phase due to production of ammonia, and with $3 \%$ glucose the $\mathrm{pH}$ 
Table 2. The effect of dissolved oxygen in the fermenter on production of ascosteroside by $A$. amphitricha during fermentation with $1 \%$ glucose at $28^{\circ} \mathrm{C}$ and 1 VVM.

\begin{tabular}{cccc}
\hline $\begin{array}{c}\text { Dissolved } \\
\text { oxygen }(\%)^{\mathrm{a}}\end{array}$ & $\begin{array}{c}\text { Agitation rate } \\
(\mathrm{rpm})\end{array}$ & $\begin{array}{c}\text { Back pressure } \\
(\text { bar })\end{array}$ & $\begin{array}{c}\mathrm{Sc} 7 \\
(\mathrm{~mm})^{\mathrm{b}}\end{array}$ \\
\hline 0 & 200 & 0.3 & 0 \\
0 & 350 & 0.3 & 0 \\
26 & 500 & 0.3 & 2.5 \\
40 & 500 & 0.3 & 11.5 \\
70 & 500 & 0.4 & 10.0 \\
79 & 500 & 0.4 & 9.5 \\
\hline
\end{tabular}

a The lowest level of dissolved oxygen detected during growth in the fermenter.

b Highest level of ascosteroside detected during the fermentation.

remained below 5.0, only increasing towards the end of the fermentation. Oxygen levels in the fermenter with $1 \%$ glucose dropped down to $70 \%$, and this depletion in oxygen coincided with the onset of stationary phase and initiation of production of ascosteroside. In the fermenter with $3 \%$ glucose, the lowest level of oxygen $(60 \%)$ occurred after the beginning of stationary phase. Similar levels of ascosteroside were produced under the two conditions.

Effect of Temperature on Ascosteroside Production

Incubation of $A$. amphitricha during growth in flask culture by shaking with $1 \%$ glucose at temperatures below $28^{\circ} \mathrm{C}$ resulted in an increase in the amount of ascosteroside produced (Table 3 ). Highest production of ascosteroside occurred when the organism was grown at $16^{\circ} \mathrm{C}$, and levels were reduced with an increase in the incubation temperature, with lowest levels at $32^{\circ} \mathrm{C}$. In the fermenter with $3 \%$ glucose, higher production of ascosteroside occurred at $25^{\circ} \mathrm{C}$ compared to $28^{\circ} \mathrm{C}$.

\section{Discussion}

The optimal conditions for the production of ascosteroside in the fermenter included using a medium containing glucose as the main carbon source, maintaining dissolved oxygen levels above a critical threshold level, and running the fermentation at temperatures below $28^{\circ} \mathrm{C}$.

The finding that ascosteroside production occurred during the non-active growth phase of the organism suggests that ascosteroside may be a metabolic sink product formed during the period of unbalanced growth in stationary phase. Biosynthesis of ascosteroside after
Fig. 4. The effect of glucose on ascosteroside production by A. amphitricha in the fermenter.

(A) Glucose concentration (open symbols) and biomass levels (closed symbols) with $3 \%$ glucose $(\mathrm{O}, 0)$ and $1 \%$ glucose ( $\square$, $\mathbf{\square}$ ). (B) Dissolved oxygen levels (open symbols) and $\mathrm{Sc} 7$ activity (closed symbols) with $3 \%$ glucose $(\mathrm{O}, \mathbf{O})$ and $1 \%$ glucose $(\square, \boldsymbol{\square})$. (C) Ammonia levels (open symbols) and $\mathrm{pH}$ (closed symbols) with $3 \%$ glucose $(\mathrm{O}, \bullet)$ and $1 \%$ glucose $(\square, \boldsymbol{\square})$.

(A)

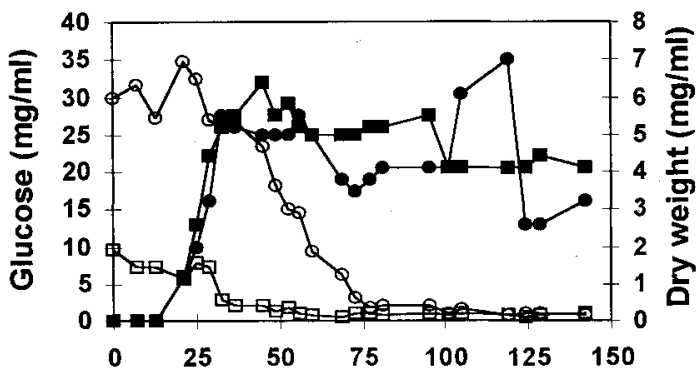

(B)

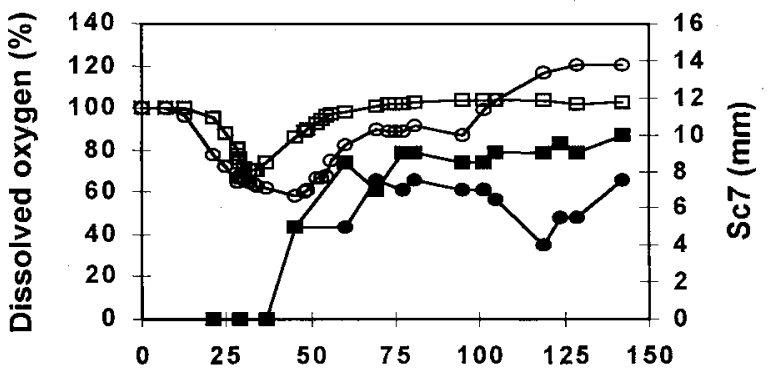

(C)

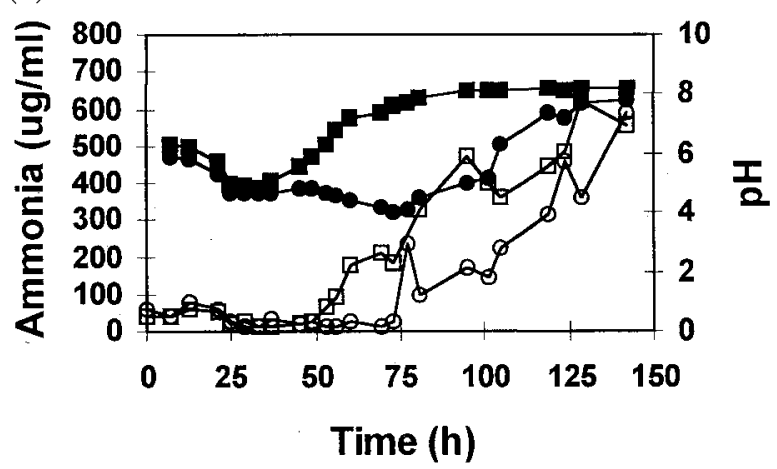

Table 3. The effect of temperature on production of ascosteroside by $A$, amphitricha during fermentation with $1 \%$ glucose in flasks.

\begin{tabular}{cc}
\hline Temperature $\left({ }^{\circ} \mathrm{C}\right)$ & $\mathrm{Sc} 7(\mathrm{~mm})$ \\
\hline 16 & 14.0 \\
21 & 12.0 \\
26 & 12.0 \\
28 & 9.0 \\
32 & 7.0 \\
\hline
\end{tabular}


active growth has ceased is probably essential to the survival of $A$. amphitricha, as the antifungal activity of the compound could prove toxic to the producer. For most antibiotic producing organisms, resistance to the producing compound occurs only in stationary phase ${ }^{5,6}$.

In many fermentations carbon source regulation influences antibiotic production, and glucose although an excellent carbon source for growth, often represses antibiotic synthesis ${ }^{7)}$. This phenomenon does not apply to $A$. amphitricha when the organism was grown in shake flasks, as production increased at $28^{\circ} \mathrm{C}$ with increasing levels of glucose (up to $3 \%$ ), and did not coincide with glucose limitation. Furthermore, the production of ascosteroside in the fermenter with $3 \%$ glucose occurred even though the residue glucose concentration was as high as $2.5 \%$.

In the biosynthesis of a number of antibiotics oxygen has been found to play a crucial role. Specific penicillin production rates decreased sharply below 30\% air saturation during growth of Penicillium chrysogenum in the fermenter, with no production at dissolved oxygen tension levels of $10 \%{ }^{8)}$. With Streptomyces clavuligenes, reduction in dissolved oxygen to almost zero delayed production of cephamycin $\mathrm{C}$, and higher levels of dissolved oxygen resulted in increased titers ${ }^{9)}$. The critical dissolved oxygen concentration of $20 \%$ was one of the most important factors in cephalosporin $\mathrm{C}$ production by Cephalosporium acremonium, and below this value repression of cephalosporin $\mathrm{C}$ production occurred and penicillin $\mathrm{N}$ concentrations increased ${ }^{10}$ ). For the optimal production of cephalosporin $\mathrm{C}$, dissolved oxygen levels were maintained at no less than $30 \%$ of saturation ${ }^{11}$. Irreversible repression of ascosteroside synthesis resulted if dissolved oxygen levels dropped below $26 \%$. A similar situation exists with Bacillus subtilis where oxygen levels during the first day of growth were critical in the production of the antibiotic iturin ${ }^{12)}$.

Due to the sterol nature of ascosteroside, the importance of oxygen in production could be attributed to its role in the biosynthetic pathway of the antibiotic. Oxygen is required for the synthesis of sterols, unsaturated fatty acids and various vitamins ${ }^{13)}$, and temperature has been shown to be important in the synthesis of a number of secondary metabolites ${ }^{14)}$. Temperature has also been shown to effect ergosterol biosynthesis in yeast, with de novo synthesis at an elevated temperature of $40^{\circ} \mathrm{C}$ being only $32 \sim 35 \%$ of that at 20 or $30^{\circ} \mathrm{C}^{15}$ ). For production of ascosteroside a temperature of $25^{\circ} \mathrm{C}$ or lower was found to be optimal. Thus, the two most critical factors affecting sterol biosynthesis in fungi, namely oxygen and temperature, also influence the production of the sterol-like antibiotic ascosteroside.

\section{Acknowledgments}

We would like to thank STEve MAMBER and Ken BroOKSHIRE for their work with the biological assays. In addition we would like to thank JoSEPH O'Sullivan and JOHN LEET for useful discussions of this work, and Rrck Belval and Steve Mamber for assistance with the graphics.

\section{References}

1) Gorman, J. A.; L.-P. Chang, J. Clark, D. R. Gustavson, K. S. Lam, S. W. Mamber, D. M. Pirnik, C. Ricca, P. B. Fernandes \& J. O'Sullivan: Ascosteroside, a new antifungal agent from Ascotricha amphitricha. I. Taxonomy, fermentation and biological activities. J. Antibiotics 49: $547 \sim 552,1996$

2) LeET, J. E.; S. Huang, S. E. Klohr \& K. D. Mcbrien: Ascosteroside, a new antifungal agent from Ascotricha amphitricha. II. Isolation and structure elucidation. J. Antibiotics 49: 553 559, 1996

3) Miller, G. L.: Use of dinitrosalicylic acid reagent for determination of reducing sugar. Anal. Chem. 31: 426 428, 1959

4) Weatherburn, M. W: Phenol-hypochlorite reaction for determination of ammonia. Anal. Chem. 39: 971 974, 1967

5) Martin, J. F. \& A. L. Demain: Control of antibiotic synthesis. Microbiol. Rev. 44: $230 \sim 251,1980$

6) WoOdRufF, H. E.: The physiology of antibiotic production: the role of the producing organism. In Biochemical studies of antimicrobial drugs. Ed., B. A. Newton \& P. E. REYNOLDS, pp. $22 \sim 46,16$ th Symposium of the Society for General Microbiology, Cambridge University Press, 1966

7) Demain, A. L. \& A. FANG: Emerging concepts of secondary metabolism in actinomycetes. Actinomycetol. 9: $98 \sim 117,1995$

8) VARdar, F. \& M. D. LiLly: Effect of cycling dissolved oxygen concentrations on product formation in penicillin fermentations. Eur. J. Appl. Microbiol. Biotechnol. 14: $203 \sim 211,1982$

9) Rollins, M. J.; S. E. Jensen \& D. W. S. Westlake: Effect of aeration on antibiotic production by Streptomyces clavuligenes. J. Ind. Microbiol. 3: 357 364, 1988

10) Zhou, W.; K. Holzhauer-Rieger, M. Dors \& K. SCHUGERL: Influence of dissolved oxygen concentration on the biosynthesis of cephalosporin C. Enzyme Microbiol. Technol. 14: 848 854, 1992

11) Soln, Y.-S.; K.-C. LEe, Y.-H. KoH \& G.-H. GiL: Changes in cellular fatty acid composition of Cephalosporium acremonium during cephalosporin $\mathrm{C}$ production. Appl. Environ. Microbiol. 60: $947 \sim 952,1994$

12) Ohno, A.; T. Ano \& M. Shoda: Effect of temperature change and aeration on the production of the antifungal peptide antibiotic iturin by Bacillus subtilis NB22 in liquid cultivation. J. Ferment. Bioeng. 75: $463 \sim 465,1993$

13) Goldfine, H. \& K. Bloch: Oxygen and biosynthetic reactions. In Control Mechanisms in Respiration and Fermentation. Ed., B. Wright, pp. $81 \sim 103$, 8th Sym- 
posium of the Society for General Physiology, Ronald Press, New York, 1963

14) WeinBerG, E. D.: Secondary metabolism: control by temperature and inorganic phosphate. In Developments in Industrial Microbiology. Ed., E. D. Murray \& A. W.
Bourquin, Vol. 15, pp. $181 \sim 194$, 13th General Meeting of the Society for Industrial Microbiology, 1974

15) Shimizu, I. \& H. KATSUKI: Effect of temperature on ergosterol biosynthesis in yeast. J. Biochem. 77: 1023 $1027, .1975$ 